\title{
Perceptions of Professional Nurses in Rural Hospitals of the Limpopo Province Regarding Nursing Care of Patients with Human Immuno- deficiency Virus and Acquired Immunodeficiency Syndrome
}

\author{
Thelmah Xavela Maluleke ${ }^{1 *}$, Bumani Solomon Manganye ${ }^{2}$ and Rachel Tsakani Lebese ${ }^{2}$ \\ ${ }^{1}$ Professor, HSRC - Pretoria, Human Sciences Research Council (HSRC), Private Bag X41, Pretoria, South Africa \\ ${ }^{2}$ University of Venda, South Africa
}

\begin{abstract}
This was a qualitative study conducted in one regional and two district hospitals in the rural areas of the Limpopo Province. Its purpose was to explore and describe the perceptions of HIVIAIDS trained professional nurses regarding nursing care that is rendered to PLWHA in their own wards or units. Three rural hospitals of the Limpopo Province, one regional and two district hospitals participated in the study. Purposive sampling was used to select the wards and professional nurses who participated in the study. A total of three focus group discussion were conducted, one at each hospital. Individual interviews were conducted with professional on what they consider to be good and proper nursing care for HIV positive patients. The participants were of the view that nursing care for HIV and AIDS patients should be non-discriminatory, following precautionary measures to protect patient, self and other, giving health education, support and counselling and maintain confidentiality. Knowledge of HIV and AIDS, respect for human dignity, trusting nurse-patient relationship, and confidence in the caring relationship were identified as the main contributory factors to giving good nursing care to HIV-positive patients. To improve the quality of care for PLWHA all nurses working in the wards should have advanced knowledge and skills in the care of HIV and AIDS patients.
\end{abstract}

Keywords: Human immuno-deficiency virus (HIV); Acquired immunodeficiency syndrome (AIDS); Professional nurses; PLWHA; Nursing care

\section{Introduction}

Although there is evidence that the prevalence of the Human Immuno-Deficiency Virus (HIV) and Acquired Immunodeficiency Syndrome (AIDS) is declining or has stabilised in some countries including south, its impact remains a major health care challenge that affects families, communities and health care systems. In 2011, South Africa was estimated to have a prevalence of $10.6 \%$ with 5.38 million of its population living with HIV and AIDS. Approximately $16.6 \%$ of the adult population were HIV positive and only 1.1 million of them were receiving Anti-Retroviral Therapy (ART). Between 2001 and 2010 a steady increase in prevalence among adults of child bearing age and a decline among children has been observed [1].

In health care facilities the increasing number of admissions due to HIV and AIDS adds pressure to the already over stretched health care services compromising the quality of care people living with HIV and AIDS (PLWHA) receive. The inferior quality of care given to PLWHA is further confounded by issues of stigma and discrimination by health care workers including nurses. HIV related stigma and discrimination is mainly caused by fear of contagion and inadequate knowledge of the disease [2].

As nurses play a crucial role in the management of HIV and AIDS patients, the World Health Organisation (WHO) and other organisations have initiated programmes that would build health care workers' capacity in relation to HIV and AIDS management and care. These specialised HIV and AIDS programmes included the nursing management of HIV positive patient meant to allay nurses' fear of contagion and restore their ability to give quality care and confidence in caring for HIV positive patients. Nursing management of HIV and AIDS in health care facilities included the following: education and information on HIV and AIDS; preventing HIV transmission in health care settings; preventing HIV transmission through sex; managing sexually transmitted infections; preventing mother to child transmission; Voluntary Counseling and Testing (VCT); preventing the progression of HIV infection to AIDS; quality care for PLWHA and clinical management and treatment for PLWHA [3].

The Limpopo Province like many other provinces in South Africa benefited from these initiatives and took many of their nurses for training. The intention of this study was to find out how professional nurses trained in these specialised HIV programmes perceive the nursing care that is rendered to HIV positive patients in their own wards or units. The purpose of this study was to explore and describe the perceptions of HIV/AIDS trained professional nurses regarding nursing care that is rendered to PLWHA in their own wards or units.

\section{Material and Methods}

\section{Research design}

This was a qualitative study aimed at exploring and describing professional nurses' perceptions of appropriate nursing care for HIV positive patients. Three rural hospitals of the Limpopo Province, one regional (Hospital A) and two district hospitals Hospital B \& C) participated in the study. Participants for the study were professional

*Corresponding author: Thelmah Xavela Maluleke, Professor, HSRC-Pretoria Human Sciences Research Council (HSRC), Private Bag X41, pretoria, 134 Pretorius Street, Pretoria, South Africa, Tel: +27 12302 2359, 0825888582 or 0799856146; Fax: +27 12302 2525; E-mail: TMaluleke@hsrc.ac.za

Received September 24, 2012; Accepted October 22, 2012; Published October 29, 2012

Citation: Maluleke TX, Manganye BS, Lebese RT (2012) Perceptions of Professional Nurses in Rural Hospitals of the Limpopo Province Regarding Nursing Care of Patients with Human Immuno-deficiency Virus and Acquired Immunodeficiency Syndrome. J AIDS Clinic Res 3:176. doi:10.4172/2155-6113.1000176

Copyright: (c) 2012 Maluleke TX, et al. This is an open-access article distributed under the terms of the Creative Commons Attribution License, which permits unrestricted use, distribution, and reproduction in any medium, provided the original author and source are credited. 
Citation: Maluleke TX, Manganye BS, Lebese RT (2012) Perceptions of Professional Nurses in Rural Hospitals of the Limpopo Province Regarding Nursing Care of Patients with Human Immuno-deficiency Virus and Acquired Immunodeficiency Syndrome. J AIDS Clinic Res 3:176. doi:10.4172/21556113.1000176

Page 2 of 4

\begin{tabular}{|c|c|c|c|c|c|c|}
\hline Hospital & $\begin{array}{c}\text { Total number } \\
\text { of P/N }\end{array}$ & ARV & VCT & PMTCT & $\begin{array}{c}\text { Couple } \\
\text { counselling }\end{array}$ & $\begin{array}{c}\% \text { of those with } \\
\text { special training }\end{array}$ \\
\hline A & 228 & 8 & 80 & 13 & 05 & 46.49 \\
\hline B & 91 & 12 & 18 & 13 & 03 & 50.55 \\
\hline C & 145 & 04 & 35 & 26 & 04 & 47.59 \\
\hline Total & $\mathbf{4 6 4}$ & $\mathbf{2 4}$ & $\mathbf{1 3 3}$ & $\mathbf{5 2}$ & $\mathbf{1 2}$ & $\mathbf{4 7 . 6 3}$ \\
\hline
\end{tabular}

(NB: Some had more than one of these qualifications)

Table 1: Professional nurses who have received advanced training in specialised aspects of HIV and AIDS patient care.

nurses who have received advanced training in specialised aspects of HIV and AIDS patient care. Table 1 indicates the total number of professional nurses that had specialised HIV/AIDS training in the three hospitals. The table shows that more than $50 \%$ of all professional nurses employed in the three hospitals had not received specialised training on HIV and AIDS.

\section{Population and sampling}

The population in this study included all professional nurses registered with the South African Nursing Council (SANC) employed in the three hospitals and had received specialised training on HIV and AIDS namely, VCT, ARV, PMTCT and couple counselling. Purposive sampling was used to select the wards and professional nurses who participated in the study. Adult medical wards and maternity wards were selected in all the participating hospitals. The reason for selecting these wards was that the majority of known confirmed HIV positive patients are admitted and cared for in these wards. A total of thirty-four $(n=37)$ participants were purposively sampled using the following criteria: The participant must be a professional nurse working in a medical ward or maternity ward and caring for HIV positive patients; have at least one year experience working as a professional nurse caring for HIV positive patients; have attended one or more HIV related specialised training.

\section{Data collection}

Data were collected through individual semi-structured interviews $(n=9)$ and three focus group discussions $(n=28)$. A total of three FGDs were conducted, one at each hospital. Individual interviews were conducted with professional nurses in charge of HIV and AIDS care and programmes in the three participating hospitals. Permission to use an audio-recorder and research assistant was sought from the participant $[4,5]$.

\section{Data analysis}

All collected data were transcribed verbatim from the tape recordings and translated into English by a language practitioner and analysed. Tech's eight steps of data analysis were then used to analyse the data. The transcribed information was individually analysed and categories formed to allow the researchers to identify similarities, differences and relationships. The categories were then grouped into themes and interpreted [6].

\section{Ethical consideration}

Ethical consideration included obtaining permission from the University of Venda Ethics Provincial Department of Health, Chief Executive Officer of the hospitals and Operational Managers of the wards. Written informed consent was obtained from each participant before the interviews and focus group discussions. Use of audiotape and research assistants was also explained to the informants [7]. Anonymity of participants was maintained and assurance given that all information would be treated in absolute confidence. All data collected was safely stored and anonymity of the participants maintained throughout the process.

\section{Results and Discussions}

The perceptions of HIV and AIDS special trained professional nurses could be divided into three themes as indicated above: description of nursing care for HIV positive patients; factors contributing to good and proper care for HIV positive patients; challenges in nurse-patient relationship in the care of HIV patients.

\section{Professional nurses' description of nursing care for HIV positive patients}

The participant was of the view that nursing care for PLWHA should be good and proper nursing. Their description of good and proper nursing care was indicated as caring for the patient like they are your own children or relatives or friend without any form of discrimination, following precautionary measures to protect patient, self and other, giving health education, support and counselling and maintain confidentiality. The World Health Organization describes the care of PLWHA as Comprehensive HIV/AIDS Care that is divided into four categories, clinical management, nursing care, counselling and home and community-based care. The participants in the current study included counseling as one of the activities in nursing care [8].

The participants' description of good and proper nursing care was mainly about rendering basic nursing skills which includes: maintaining good personal hygiene, infection prevention, feeding the patient, being respectful to the patient and taking care of their emotional well being. Appropriate nursing care was described as nursing care that is specific to HIV and AIDS mentioned above was centred on supporting the patients in accepting their HIV and AIDS status, giving antiretroviral therapy as prescribed and prevention of discriminatory practices by nurses. One participant said "I think the most important thing in caring for HIV patient is to nurse them with a smile and make them feel important as everyone else including themselves has lost hope. We need to spend more time with them and counsel them to help them accept their condition."

The participants description of nursing care for HIV and AIDs patient was similar to the nursing care of HIV positive patients described by the World Health Organization that has the following nursing activities: maintenance and promotion of hygiene and nutrition, enforcement of infection control practices, provision of palliative and terminal care, education of family and community members in providing care, preventive education and promotion of condom use [8].

Although these HIV and AIDS special trained nurses were committed to good and proper care for the HIV positive patients they were concerned about the care HIV patients were receiving in the ward in the hands of some untrained professional nurses and junior staff members. In their view professional nurses and junior staff members who were not trained on HIV and AIDS had discriminatory practices against patients living with HIV and AIDS in the wards. As one of the participant indicated, "In our ward we have both senior and junior staff members who have inadequate knowledge about HIV and AIDS bring all the myths and beliefs from the community to the wards. They do not respect the patients and often display discriminatory tendencies. The problem is that some of us here do not reprimand them. It is our responsibility to reprimand them and teach them about this disease. It does not help us or the patient if we keep quiet and complain in our small corners."

The behaviours mentioned above violate three of the ethical principles of nursing, namely respect for patients, protection of patient against physical or psychological harm and treating all patients equally 
Citation: Maluleke TX, Manganye BS, Lebese RT (2012) Perceptions of Professional Nurses in Rural Hospitals of the Limpopo Province Regarding Nursing Care of Patients with Human Immuno-deficiency Virus and Acquired Immunodeficiency Syndrome. J AIDS Clinic Res 3:176. doi:10.4172/21556113.1000176

Page 3 of 4

despite their social standing and status. Discriminatory practices against PLWHA by nurses also violate the ethical principle of confidentiality, because more often than not such practices are accompanied by utterances that often give away the diagnosis of the patient.

\section{Implementing precautionary measures during care giving}

The majority of the participants were of the view that proper implementation of precautionary measures was a very important component in the nursing care of PLWHA as they protect both patients and nursing staff. Most of them thought that precautionary measures were followed properly in their wards. However, some were concerned about some practices that exist in their wards. As one of them indicated "I would say, in the maternity ward the majority of the nurses wear the appropriate protective clothing as required. However, there are some professional nurses who do not follow the precautionary measures properly. They seem to follow precautionary measures to protect themselves from getting infected but exposed their patients to cross infection. Some of them especially those working in the neonatal wards wear the same pair of gloves from one patient to another without washing or disinfecting them. As HIV-positive patients have low immunities this could introduce new infections that might result in their death."

These findings resonate with suggestions made Walusimbi and Okonsky [9] that having knowledge about precautions against HIV and prevention of cross infection reduces the fear of contagion among staff and ensure positive outcomes of the illness. When universal precautions are applied appropriately it might not be necessary to isolate HIVpositive patients unless they have tuberculosis or other opportunistic infections that require isolation [10].

Some participants indicated that nurses did follow universal precautionary measures to prevent cross infection in the wards. They used aseptic techniques when handling infectious fluids and proper disposal of waste. It was reported that in maternity wards they avoid artificial rapture of membranes and performance episiotomies as precautionary measures. One participant said "We make sure that all the staff members are aware of the universal precaution, like wearing of gloves, proper waste management. They all know that the red plastic is for medical waste and the black one for general waste. Junior nurses are also taught in wound dressing how to promote wound healing here in the ward." According to Curry et al. [11] student nurses should be trained to understand that adherence to procedures such as universal precautions significantly reduce the risk of contagion when treating patients with AIDS. Similarly, Mahendra et al. [12] reported that trained nurses who worked in New Delhi, India took adequate precautions to protect themselves and patients. It is also important to make health care workers aware that non-adherence to precautionary measure is unethical because it harms the patients through cross infection.

\section{Giving health education, support and counselling to patients}

During interviews and focus group discussions participants indicated the importance of supporting patients by giving them health education and counselling until they had accepted their HIV status. Participants further explained that they counselled most patients and that the HIV and AIDS statistics had improved as a result. This statement suggests that in their daily statistics, nurses indicate the number of HIV patients in her ward or unit and one would hope that the patient's name is not indicated as that would be a violation of the patient's confidentiality rights. The importance of educating and reprimanding junior staff members to accept patients who were HIV positive was also stressed as a way of supporting patients. Literature indicates that the major aspects involved in the study of HIV and AIDS are education, prevention, treatment and support to people living with HIV and AIDS, as well as those affected by it. The cornerstone of an effective strategy against HIV and AIDS is education [13].

\section{Maintaining confidentiality}

The participants indicated that nursing care of HIV patients requires nurses to maintain confidentiality and privacy during care giving. They are expected to always conduct counseling sessions in a private room and should not disclose the patient's HIV status without the patient's permission. In their view maintaining confidentiality protects the patient from stigmatization and discrimination by health care workers. Maintaining confidentiality enables HIV positive patients to be treated fairly in the wards.

\section{Factors contributing to good and proper care for HIV-positive patients}

Knowledge of HIV and AIDS, respect for human dignity and trust: Knowledge of HIV and AIDS, respect for human dignity, trusting nurse-patient relationship, and confidence in the caring relationship were identified as the main contributory factors to giving good nursing care to HIV-positive patients. Participants indicated that most of the professional nurses who had received training on HIV and AIDS tended to have positive attitudes towards caring for HIV-positive patients. This is an indication that there is a relationship between the attitudes that influence the type of nursing care and the level of knowledge that nurses have. These professional nurses understand the condition well and respect human dignity. Furthermore there was some excitement amongst the participants that their knowledge has helped them in winning their patients' confidence and trust. One participant said "I think the most important thing is that the courses that we attended, the counselling and VCT courses gave us information. So when you have got knowledge, you are empowered, so with empowerment you know exactly what to do, so we don't have fear". Participants advocated for more courses that would teach all staff members about HIV and AIDS and the mode of spread to improve the quality of care given to HIV-positive patients.

The findings of a study done by Walusimbi and Okonsky [9] and Rahlenbeck [14] show that as the level of knowledge increased fear of the disease decreased. A study done by Salyer et al. [15] indicates that higher knowledge levels and more positive attitudes were reported by those midwives who had attended a formal HIV education programme or who had nursing education. Similarly, Li et al. [16] finding suggests that service providers with better knowledge of HIV reported less internalised shame. They concluded that HIV training and knowledge might help providers to understand the level of risk associated with caring for HIV and AIDS patients better, and therefore would probably reduce their stigma and shame.

Challenges related to nurse-patient relationship in the care of HIV patients: The participants indicated that the relationship between the nurse and patient has its own challenges that come from both parties that are involved in this relationship. There could be over attachment or dependence between of the patient to a particular nurse whereby the patient would unreasonable sought the care of the nurse. For example, the patient could call the nurse at night or when she is on leave for minor problems that could be sorted out by the nurses that are taking care of her during that time. They blamed this behaviour on the lack family support to HIV patients. Participants also indicated that nurses themselves also get too attached to their patients that often result 
Citation: Maluleke TX, Manganye BS, Lebese RT (2012) Perceptions of Professional Nurses in Rural Hospitals of the Limpopo Province Regarding Nursing Care of Patients with Human Immuno-deficiency Virus and Acquired Immunodeficiency Syndrome. J AIDS Clinic Res 3:176. doi:10.4172/21556113.1000176

Page 4 of 4

in stress and depression when the patient's condition deteriorates and death occurs. In some cases nurses become so attached to the patient to the extent of neglecting their families, personal relationships and family responsibilities.

According to Carr [17] positive interpersonal relationships between patients and providers the positive interpersonal relationship enhances the health care experience for the patient which is an important outcome in the nursing care of terminally ill patients. There is evidence that some HIV patients use their personal relationships with their health care providers as part of their personal support networks. These personal connections might evolve into long-term relationships and remain supportive for long periods of time. However, this relationship might negatively affect the nurse when the patient passes on [18]. In a study conducted by Carr some nurses indicated that they felt bad to think that there will be a time when their relationship had to end because of the passing away of their patient. A similar view was also expressed by participants in the current study. Although sthe nurse-patient relationship has its own challenges its existence plays a major role in the care of HIV patients in the wards and its existence is therapeutic for both parties. Nurturing the existing and inculcation of a healthy therapeutic relationship between patients and nurses in the ward could lead to care of HIV patients without stigma and discrimination.

\section{Conclusion}

The study explored and described professional nurses' perceptions of appropriate nursing care for HIV positive patients. Three rural hospitals of the Limpopo Province participated in the study. Interviews and focus group discussions were held with 37 professional nurses who had advanced training in specialised aspects of HIV and AIDS patient care in order to determine their views on appropriate nursing care for PLWHA. In their view nursing care for HIV and AIDS patients should be non-discriminatory, follow precautionary measures, educate, counsel and support the patient, and maintain confidentiality at all times. To be able to give proper nursing care the nurse must have knowledge of HIV and AIDS and respect for human dignity. It was also indicated that lack of skills and knowledge of HIV and AIDS, and fear of contracting the disease were the main factors contributing to improper nursing care of HIV-positive patients in their wards. The importance of following the universal precautionary measures during the care of PLWHA to protect nurses and patients was emphasised. Training of all health workers in the wards on HIV and AIDS and provision of support for the nurses who care for HIV-positive were recommended as best methods of improving the quality of care for PLWHA.

\section{References}

1. Statistics South Africa (2011) Mid-Year Population Estimates. Statistical Release.

2. Green G (1995) Attitudes towards people with HIV: Are they as stigmatizing as people with HIV perceive them to be? Soc Sci Med 41: 557-568.

3. World Health Organisation (2009) Priority interventions HIVIAIDS prevention treatment and care in the health sector. World Health Organization, HIVIAIDS Department.

4. De Vos AS (2005) Research at grassroots: A premier for the caring professions JL Van Schaik Academic, Pretoria.

5. Brink H, Walt CV (2005) Fundamentals of research methodology for healthcare professionals. Juta \& Company Ltd, Cape Town.

6. Creswell JW (2002) Research design: Qualitative, Quantitative, and Mixed Methods Approaches. Sage London.

7. Burns N, Groove SK (2005) The practice of Nursing Research: conduct, critique, and utilization. WB Saunders, Philadelphia.

8. World Health Organisation (2011) HIVI AIDS Care at the Institutional, Community and Home Level. SEARO Publications on HIV/ AIDS, South East Asia Regional Office.

9. Walusimbi M, Okonsky JG (2004) Knowledge and attitudes of nurses caring for patients with HIVIAIDS in Uganda. Appl Nurs Res 17: 92-99.

10. Kermode M, Holmes W, Langkham B, Thomas MS, Gifford S (2005) HIVrelated knowledge, attitudes and risk perception amongst nurses, doctors and other healthcare workers in rural India. Indian J Med Res 122: 258-264.

11. Currey CJ, Johnson M, Ogden B (1990) Willingness of health-professions students to treat patients with AIDS. Acad Med 65: 472-474.

12. Mahendra VS, Gilborn L, Bharat S, Mudoi R, Gupta I, et al. (2007) Understanding and measuring AIDS-related stigma in health care settings: A developing country perspective. SAHARA J 4: 616-625.

13. Tshililo AR (2005) The experiences of family members in caring for HIV and AIDS patients at home in Limpopo province at Vhembe district and in rura communities. Masters dissertation: University of Venda.

14. Rahlenbeck SI (2004) Knowledge, Attitude, and practice about AIDS and condom utilization among health workers in Rwanda. J Assoc Nurses AIDS Care 15: 56-61.

15. Salyer JL, Walusimbi ML, Fitzpatrick JJ (2008) Knowledge and attitudes of Ugandan midwives regarding HIV. J Assoc Nurses AIDS Care 19: 105-113.

16. Li X, Wang H, Williams A, He G (2009) Stigma reported by people living with HIV in South Central China. J Assoc Nurses AIDS Care 20: 22-30.

17. Carr GS (2001) Negotiating trust: A grounded theory study of interpersonal relationships between persons living with HIVIAIDS and their primary health care providers. J Assoc Nurses AIDS Care 12: 35-43.

18. Shives LR (2007) Basic concepts of psychiatric-mental health nursing Lippincott Williams \& Wilkins, Philadelphia. 